\title{
Residual Axillary Burden After Neoadjuvant Chemotherapy (NACT) in Early Breast Cancer in Patients with a priori Clinically Occult Nodal Metastases - a transSENTINA Analysis
}

\author{
Residuale axilläre Metastasenlast nach neoadjuvanter \\ Chemotherapie (NAC) bei Patientinnen mit Mammakarzinom \\ im Frühstadium und a priori klinisch-okkulten Lymphknoten- \\ metastasen - eine transSENTINA-Analyse
}

\section{(우 (1) $(2) \ominus$}

Authors

Hans-Christian Kolberg ${ }^{1}$, Thorsten Kühn², Maja Krajewska ${ }^{3}$, Ingo Bauerfeind ${ }^{4}$, Tanja N. Fehm ${ }^{5}$, Barbara Fleige ${ }^{6}$, Gisela Helms ${ }^{7}$, Annette Lebeau ${ }^{8}$, Annette Stäbler ${ }^{9}$, Sabine Schmatloch ${ }^{10}$, Maik Hauschild ${ }^{11}$, Lukas Schwentner ${ }^{12}$, Peter Schrenk ${ }^{13}$, Sibylle Loibl ${ }^{14}$, Michael Untch ${ }^{15}$, Cornelia Kolberg-Liedtke ${ }^{16}$

Affiliations

1 Department of Gynecology and Obstetrics, Marienhospital Bottrop, Bottrop, Germany

2 Interdisciplinary Breast Centre, Department of Gynecology and Obstetrics, Klinikum Esslingen, Esslingen, Germany

3 Institute of Biometry and Clinical Epidemiology, Charité University Hospital Berlin, Berlin, Germany

4 Department of Gynecology and Obstetrics, Klinikum Landshut, Landshut, Germany

5 Department of Gynecology and Obstetrics, University Hospital Düsseldorf, Düsseldorf, Germany

6 Department of Pathology, Multidisciplinary Breast Centre, Helios Klinikum Berlin-Buch, Berlin, Germany

7 Department of Gynecology and Obstetrics, University Medical Centre Tübingen, Tübingen, Germany

8 Department of Pathology, University Medical Center Hamburg-Eppendorf, Hamburg, Germany

9 Department of Pathology, University of Tübingen, Tübingen, Germany

10 Breast Centre, Elisabeth Hospital Kassel, Kassel, Germany

11 Department of Gynecology and Obstetrics, Health Center Fricktal, Rheinfelden, Switzerland

12 Gynova, Reith, Austria

13 Breast Competence Centre, Kepler University Hospital, Linz, Austria

14 German Breast Group, Neu Isenburg, Germany

15 Department of Gynecology and Obstetrics, Multidisciplinary Breast Centre, Helios Klinikum Berlin-Buch, Berlin, Germany

16 Department of Gynecology and Obstetrics, University Hospital Essen, Essen, Germany
Key words prediction of lymph node status, primary systemic therapy, SENTINA trial, sentinel lymph node biopsy

Schlüsselwörter

prädiktiver Wert des Lymphknotenstatus, primäre Systemtherapie, SENTINA-Studie, Sentinel-Lymphknoten-Biopsie
received
20.8. 2020
accepted after revision
30.10.2020

Bibliography

Geburtsh Frauenheilk 2020; 80: 1229-1236

DOI 10.1055/a-1298-3453

ISSN 0016-5751

(C) 2020. The Author(s).

This is an open access article published by Thieme under the terms of the Creative Commons Attribution-NonDerivative-NonCommercial-License, permitting copying and reproduction so long as the original work is given appropriate credit. Contents may not be used for commercial purposes, or adapted, remixed, transformed or built upon. (https://creativecommons.org/licenses/by-nc-nd/4.0/)

Georg Thieme Verlag KG, Rüdigerstraße 14,

70469 Stuttgart, Germany

Correspondence

Priv.-Doz. Dr. med. Hans-Christian Kolberg

Department of Gynecology and Obstetrics,

Marienhospital Bottrop

Josef-Albers-Straße 70, 46236 Bottrop, Germany

hans-christian.kolberg@mhb-bottrop.de 


\section{ABSTRACT}

Background Among patients with breast cancer undergoing neoadjuvant chemotherapy (NACT), the association between pathological complete remission ( $\mathrm{pCR}$ ) in the breast and clinical/pathological parameters is well established, whereas the association between these parameters and residual axillary involvement after NACT remains unclear.

Methods Patients with clinically occult nodal metastases (i.e. negative by clinical assessment but positive by SLNB prior to NACT, i.e. Arm B of the SENTINA trial) were included in the presented analysis. All patients received a second sentinel lymph node biopsy (SLNB) and axillary dissection after NACT. Univariate and multivariate analyses were carried out to evaluate the association between clinical/pathological parameters and axillary involvement after NACT.

Results Arm B of the SENTINA study contained 360 patients, 318 of which were evaluable for this analysis. After NACT, 71/ $318(22.3 \%)$ patients had involved SLNs or non-SLNs after NACT. Overall, 71/318 (22.3\%) patients achieved a pCR in the breast. Associations of extranodal spread, lack of multifocality and pCR in the breast with residual axillary burden were statistically significant. In a descriptive analysis including all patients with clinically negative axilla before NACT in the SENTINA trial $1.2 \%$ of triple negative (TN) patients and $0.5 \%$ of $\mathrm{HER} / 2$ positive patients had residual axillary disease in case of a breast $\mathrm{PCR}$.

Conclusions Patients in the SENTINA trial with clinically negative axilla and involved SLNs still carried a significant risk of nodal metastases after NACT. However, the risk of residual axillary burden was particularly low in TN and HER/2 positive tumors in case of a breast $\mathrm{PCR}$.

\section{ZUSAMMENFASSUNG}

Hintergrund Der Zusammenhang zwischen pathologischer Komplettremission ( $p C R$ ) der Brust und klinischen/pathologischen Parametern ist bei Brustkrebspatientinnen, die sich einer neoadjuvanten Chemotherapie (NAC) unterziehen, bekannt. Noch nicht geklärt ist aber der Zusammenhang zwischen diesen Parametern und der residualen axillären Lymphknotenlast nach NAC.

Methoden In dieser Studie wurden Patientinnen mit klinischokkulten Lymphknotenmetastasen (d.h. klinisch-negativ, aber SLN-positiv vor NAC; d. h. aus dem Arm B der SENTINAStudie) aufgenommen. Bei allen Patientinnen wurde eine zweite Sentinel-Lymphknoten-Biopsie (SLNB) sowie eine axilläre Lymphknotendissektion nach der NAC durchgeführt. Es wurden univariate und multivariate Analysen durchgeführt, um den Zusammenhang zwischen klinischen/pathologischen Parametern und axillärem Lymphknotenbefall nach NAC zu bestimmen.

Ergebnisse Es wurden 360 Patientinnen aus dem Arm B der SENTINA-Studie in diese Studie aufgenommen, die Daten von 318 dieser Patientinnen wurden analysiert. Nach der NAC wurde bei 71/318 (22,3\%) Patientinnen ein Befall der SLN oder Non-SLN festgestellt. Bei insgesamt 71/318 (22,3\%) Patientinnen konnte eine pCR der Brust erreicht werden. Der Zusammemhang zwischen extranodaler Ausbreitung, fehlender Multifokalität sowie pCR der Brust und der residualen axillären Lymphknotenlast war statistisch signifikant. Bei der deskriptiven Analyse aller Patientinnen mit klinisch-negativen axillären Lymphknoten vor NAC in der SENTINA-Studie hatten 1,2\% der triple-negativen (TN) Patientinnen und 0,5\% der HER/2-positiven Patientinnen eine residuale axilläre Tumorlast trotz $\mathrm{pCR}$ der Brust.

Schlussfolgerungen Patientinnen der SENTINA-Studie mit klinisch-negativen axillären Lymphknoten und SentinelLymphknoten-Befall haben ein signifikantes Risiko für nodale Metastasen nach NAC. Allerdings ist das Risiko einer residualen axillären Tumorlast besonders gering bei Frauen mit pathologischer Komplettremission der Brust und triple-negativen oder HER/2-positiven Tumoren.

\section{Background}

It is a historical paradigm that axillary lymph node involvement is not only a strong prognostic factor in early breast cancer [1] but also plays an important role in decision making regarding systemic therapy $[2,3]$. However, the necessity of axillary surgery in every case of early breast cancer has been questioned in the recent past. On one hand the therapeutic value of the removal of involved lymph nodes is no longer generally accepted [4], on the other hand decisions for and against chemotherapy may be guided by biological factors such as multigene assays not only in node negative cases $[5,6]$ but also in node positive early breast cancer [7]. In the setting of primary surgery it has been shown that during breast conserving surgery in combination with breast irradiation patients with one or two involved sentinel lymph nodes (SLN) do not benefit from axillary dissection [8]. The INSEMA trial randomized patients treated with primary surgery to undergo sentinel lymph node biopsy (SLNB) or not, thereby advancing the concept of de-escalation of axillary intervention even further. However, results are still pending [9].

In the context of neoadjuvant chemotherapy (NACT) the feasibility of SLNB in selected patients has been demonstrated in prospective clinical trials [10-12]. However, even de-escalated axillary surgery such as SLNB may result in a significant deterioration of quality of life in $23 \%$ of patients and a rate of lymphedema in more than $8 \%$ of patients even in a short-term follow-up of 3 years [13]. 


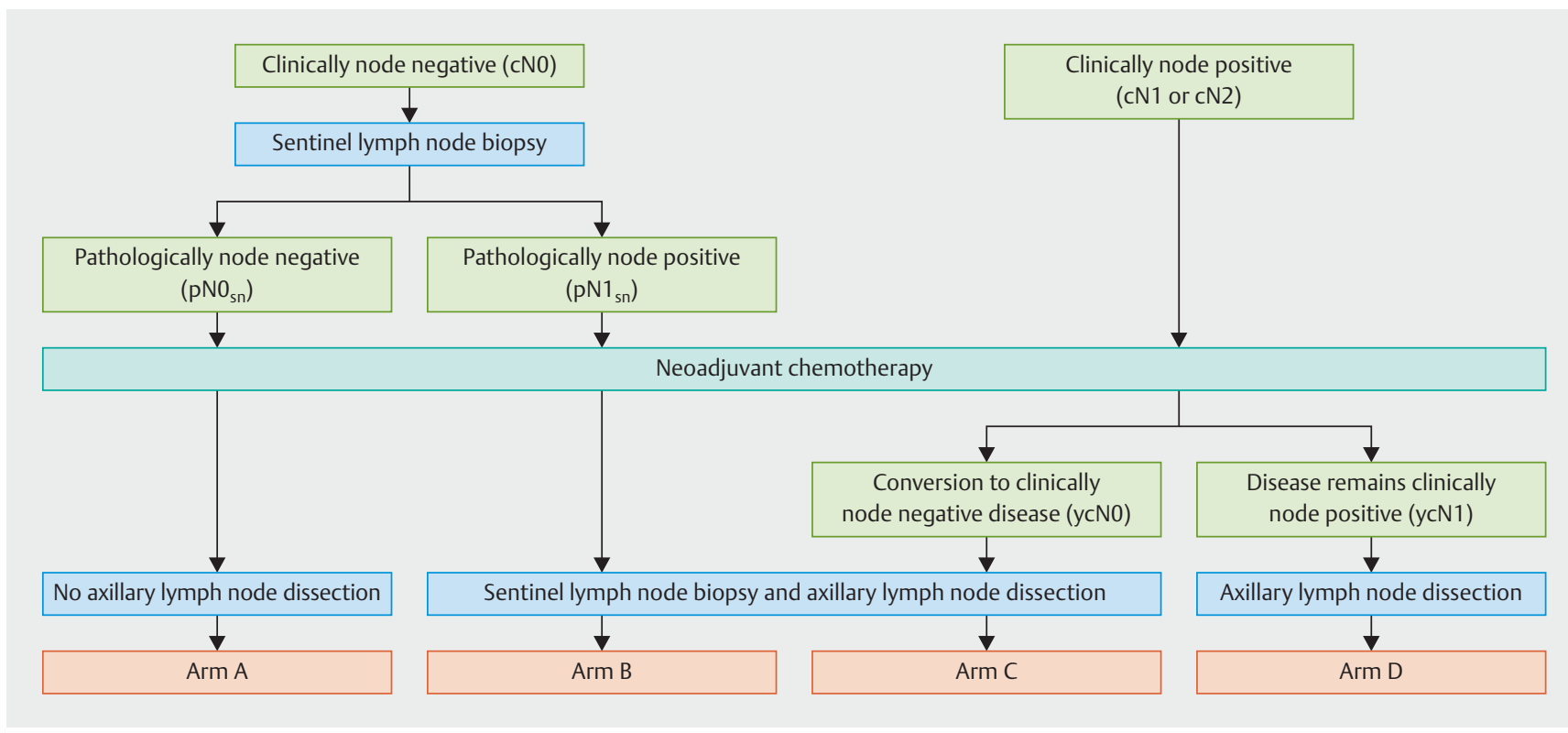

- Fig. 1 Design of the SENTINA trial (from [10]).

Patients with a low risk of residual axillary involvement after NACT could benefit from the omission of axillary intervention, if they could be identified prior to surgery. The association between pathological complete response (pCR) after NACT in the breast and clinical/pathological parameters is well established [14], whereas the role of these parameters in the prediction of residual axillary involvement after NACT is less clear. However, first signals are promising that in the future we may be able to identify a subset of patients not needing axillary surgery at all [15-17]. We used data from Arm B of the SENTINA trial [10] to analyze the association between clinical/pathological parameters and residual axillary lymph node involvement after NACT. It is important to recognize that by SLNB prior to NACT, a fraction of nodal disease is removed. Therefore, reponse rates of the SLN metastasis to NACT cannot be assessed. Consequently, our analysis allows us to assess the association between clinical/pathological parameters and rates of residual axillary burden (which may be assessed if a fraction of nodal disease has been removed previously) rather than true SLN conversion (which would require all lymph nodes to remain in situ until after NACT).

\section{Methods}

\section{The SENTINA trial}

The SENTINA clinical trial is a 4-arm prospective multicenter cohort study designed to provide reliable data for the feasibility and accuracy of a standardized SLNB procedure in different settings prior to and after primary systemic therapy. 1737 patients from 104 institutions were categorized into four treatment arms according to the result of clinical axillary staging (including ultrasound examination) before and after chemotherapy. The methods and results of the SENTINA trial have been reported previously [10]. The trial design is shown in > Fig. 1.

Patients with clinically occult nodal metastases (Arm B of the SENTINA trial) were included in the presented analysis. Clinically occult nodal metastases were defined as axillary nodes that were negative by clinical assessment (i.e. palpation and ultrasound) but found to contain nodal metastases upon SLNB prior to NACT. All patients received SLNB before and a second SLNB and axillary dissection after NACT. For the descriptive analysis we included patients from Arm A of the SENTINA trial who presented with a clinically node negative axilla and showed no involvement of SLNs prior to NACT. These patients received no further axillary surgery after NACT.

The SENTINA trial was approved by the ethics committee of the University of Frankfurt.

\section{Clinical/pathological parameters}

Residual axillary disease was defined as the second SLN and/or axillary non-SLNs carrying metastases after NACT. Clinical/pathological parameters analyzed were tumor diameter before and after NACT measured by ultrasound, morphology, grade, multifocality, lymphovascular invasion, hemangiosis, extranodal spread, ER positivity (defined as $\geq 1 \%$ positive cells by immunohistochemistry), PR positivity (defined as $\geq 1 \%$ positive cells), HR positivity (ER and/or PR positivity), HER2/neu status (HER2/neu positive defined as $3+$ by immunohistochemistry (IHC) or 2+ by IHC and positive by in-situ hybridization; HER2/neu negative defined as 0 or $1+$ by IHC or $2+$ and negative by in-situ hybridization), triple negative status (defined as ER and PR $<1 \%$ positive cells and HER2/neu negative as defined above), age in years and PCR in the breast. No central testing of histopathological/immunohistochemical parameters was performed. 
- Table 1 Distribution between clinical/pathological parameters and breast pCR/residual axillary involvement.

\begin{tabular}{|c|c|c|c|c|c|}
\hline \multirow[b]{2}{*}{$(n=318)$} & & \multicolumn{2}{|l|}{ PCR breast } & \multicolumn{2}{|c|}{$\begin{array}{l}\text { Involved SLN and/or non-SLN } \\
\text { after NACT }\end{array}$} \\
\hline & & Yes $(n=71)$ & No $(n=247)$ & Yes $(n=71)$ & No $(n=247)$ \\
\hline $\begin{array}{l}\text { Tumor diameter before NACT } \\
\text { (ultrasound) in } \mathrm{mm}\end{array}$ & & $\begin{array}{l}25.62(11-62) \\
(n=67)\end{array}$ & $\begin{array}{l}31.1(9.7-183) \\
(n=231)\end{array}$ & $29.84(9.7-93)$ & $29.87(9.9-183)$ \\
\hline $\begin{array}{l}\text { Tumor diameter after NACT } \\
\text { (ultrasound) in mm }\end{array}$ & & $\begin{array}{l}8.31(0-26) \\
(n=48)\end{array}$ & $\begin{array}{l}15.7(0-57) \\
(\mathrm{n}=209)\end{array}$ & $14.66(0-48)$ & $14.16(0-57)$ \\
\hline \multirow[t]{4}{*}{ Morphology } & Invasive ductal & $61(85.9 \%)$ & $198(80.2 \%)$ & $53(74.7 \%)$ & $206(83.4 \%)$ \\
\hline & Invasive lobular & $4(5.6 \%)$ & $39(15.8 \%)$ & $16(22.5 \%)$ & 27 (10.9\%) \\
\hline & $\begin{array}{l}\text { Invasive ductal/ } \\
\text { lobular }\end{array}$ & $0(0 \%)$ & $3(1.2 \%)$ & $0(0 \%)$ & $3(1.2 \%)$ \\
\hline & Others & $6(8.5 \%)$ & $7(2.8 \%)$ & $2(2.8 \%)$ & $11(4.5 \%)$ \\
\hline \multirow[t]{3}{*}{ Grade } & Low (1) & $2(3.1 \%)$ & $15(6.5 \%)$ & $6(9 \%)$ & $11(4.8 \%)$ \\
\hline & Intermediate (2) & $18(28.1 \%)$ & $142(61.5 \%)$ & $39(58.2 \%)$ & 121 (53.1\%) \\
\hline & High (3) & $44(68.8 \%)$ & $74(32 \%)$ & 22 (32.8\%) & $96(42.1 \%)$ \\
\hline \multirow[t]{2}{*}{ Multifocality } & Yes & $16(23.9 \%)$ & $52(22 \%)$ & $23(35.4 \%)$ & 45 (18.9\%) \\
\hline & No & $51(76.1 \%)$ & $184(78 \%)$ & $42(64.6 \%)$ & $193(81.1 \%)$ \\
\hline \multirow[t]{2}{*}{ LVI } & No & $56(90.3 \%)$ & $176(76.2 \%)$ & 45 (69.2\%) & 187 (82\%) \\
\hline & Yes & $6(9.7 \%)$ & $55(23.8 \%)$ & $20(30.8 \%)$ & $41(18 \%)$ \\
\hline \multirow[t]{2}{*}{ Hemangiosis } & No & 60 (97.3\%) & $223(97.4 \%)$ & 63 (98.4\%) & 220 (96.9\%) \\
\hline & Yes & $2(2.7 \%)$ & $6(2.6 \%)$ & $1(1.6 \%)$ & $7(3.1 \%)$ \\
\hline \multirow[t]{2}{*}{ Extranodal spread } & Yes & $5(7.9 \%)$ & $26(11.6 \%)$ & $13(19.7 \%)$ & $18(8.1 \%)$ \\
\hline & No & $58(92.1 \%)$ & $199(88.4 \%)$ & $53(80.3 \%)$ & 204 (91.9\%) \\
\hline \multirow[t]{2}{*}{ ER positive } & Yes & $33(47.1 \%)$ & $203(83.9 \%)$ & $56(80 \%)$ & $180(74.4 \%)$ \\
\hline & No & 37 (52.9\%) & 39 (16.1\%) & $14(20 \%)$ & $62(25.6 \%)$ \\
\hline \multirow[t]{2}{*}{ PR positive } & Yes & $22(31.9 \%)$ & $186(77.5 \%)$ & $46(67.7 \%)$ & $162(67.2 \%)$ \\
\hline & No & 47 (68.1\%) & $54(22.5 \%)$ & $22(32.3 \%)$ & $79(32.8 \%)$ \\
\hline \multirow[t]{2}{*}{ HER2 positive } & Yes & $11(15.9 \%)$ & $76(31.4 \%)$ & $11(15.9 \%)$ & $76(31.4 \%)$ \\
\hline & No & $58(84.1 \%)$ & $166(68.6 \%)$ & $58(84.1 \%)$ & $166(68.6 \%)$ \\
\hline \multirow[t]{2}{*}{ Triple negative } & Yes & $24(34.3 \%)$ & $25(10.3 \%)$ & $10(14.3 \%)$ & $39(16.1 \%)$ \\
\hline & No & $46(65.7 \%)$ & 217 (89.7\%) & 60 (85.7\%) & $203(83.9 \%)$ \\
\hline Age in years & & $\begin{array}{l}47.79(29.6- \\
79.1)(n=71)\end{array}$ & $\begin{array}{l}50.49(26.6- \\
78.5)(n=247)\end{array}$ & $\begin{array}{l}48.96 \\
(27.6-79.1)\end{array}$ & $\begin{array}{l}50.15 \\
(26.6-78.5)\end{array}$ \\
\hline \multirow[t]{2}{*}{ pCR breast } & Yes & NA & NA & $8(11.3 \%)$ & $63(25.5 \%)$ \\
\hline & No & NA & NA & $63(88.7 \%)$ & $184(74.5 \%)$ \\
\hline \multirow{2}{*}{$\begin{array}{l}\text { SLN/non SLN involved } \\
\text { after NACT }\end{array}$} & Yes & $8(11.3 \%)$ & $63(25.5 \%)$ & NA & NA \\
\hline & No & $63(88.7 \%)$ & $184(74.5 \%)$ & NA & NA \\
\hline
\end{tabular}

\section{Statistical analysis}

Exploratory univariate logistic regression analyses were carried out to evaluate the association between clinical/pathological parameters and residual axillary involvement after NACT. Factors with a significant association with residual axillary involvement in the univariate analysis were included in a multivariate logistic regression analysis. Due to the exploratory nature of the analyses, a significance level of $\alpha=0.05$ was set for all analyses without adjustment for multiple testing. To test for the quality of our dataset we also analyzed the association between clinical/pathological parameters and $\mathrm{pCR}$ in the breast. Calculations were performed using $R$ version 3.5.2 (The R Foundation) [18].

\section{Descriptive analysis}

To provide an estimate of residual lymph node involvement after NACT in the whole cohort of patients with clinically node negative disease we performed a strictly descriptive analysis of arms $A$ and $B$ of the SENTINA study, describing the distribution of involved lymph nodes by tumor biology. Arms A and B of the study (including all patients with clinically node negative disease at initial presentation) were analyzed regarding involvement of SLNs before NACT, arm B (including patients with involved SLNBs before NACT) was analyzed regarding lymph node involvement after NACT. 
- Table 2 Multivariate analysis of parameters associated with residual axillary disease after NACT.

\begin{tabular}{|l|l|l|l|}
\hline & Odds ratio & p-value & Odds ratio 95\% confidence intervall \\
\hline Morphology & & & \\
\hline " invasive ductal & 1.23 & 0.765 & $0.32-4.73$ \\
\hline " invasive lobular & 1.02 & 0.984 & $0.23-4.54$ \\
\hline " others & 1.62 & 0.74 & $0.09-27.6$ \\
\hline No multifocality & 3.02 & $<0.001$ & $1.68-5.43$ \\
\hline LVI & 1.61 & 0.12 & $0.88-2.92$ \\
\hline Extranodal spread & 3.48 & 0.02 & $1.59-7.59$ \\
\hline HER2 negative & 0.7 & 0.25 & $0.38-1.28$ \\
\hline PCR breast & 1.97 & 0.05 & $1.01-3.87$ \\
\hline
\end{tabular}

\section{Results}

\section{Study population}

Arm B of the SENTINA study included 360 patients, 318 of these were evaluable for this analysis, 42 patients were excluded because not all parameters were available. After NACT 71/318 (22.3\%) patients had involved SLNs or non-SLNs after NACT; 71/ $318(22.3 \%)$ achieved a pCR in the breast. Although the numbers are identical, it has to be mentioned that these were not the same patients.

\section{Association between PCR in the breast and clinical/pathological parameters}

In the univariate analysis we observed a significant association between $P C R$ in the breast and ER status $(p<0.0001)$, PR status $(p<0.0001)$, HER2 status $(p=0.005)$, triple negative $(T N)$ status $(p<0.0001)$, tumor size before $(p=0.009)$ and after $(p<0.0001)$ NACT, lymphovascular invasion $(p=0.019)$ lobular morphology $(p=0.043)$ and axillary involvement after NACT $(p=0.014)$.

\section{Association between residual axillary disease and clinical/pathological parameters}

Regarding residual axillary burden only the associations with lobular morphology $(p=0.018)$, lymphovascular invasion $(p=0.027)$, extranodal spread $(p=0.01)$, multifocality $(p=0.006)$, HER2 status $(p=0.014)$ and $p C R$ in the breast $(p=0.014)$ were statistically significant in univariate analysis. The distribution of clinical/pathological parameters regarding breast PCR and residual axillary disease is summarized in $>$ Table $\mathbf{1}$ descriptively.

\section{Multivariate analysis of parameters associated with residual axillary disease}

The clinical/pathological factors demonstrating a statistically significant association with residual axillary burden were included in a multivariate logistic regression analysis. Only the associations with extranodal spread (odds ratio [OR] 3.48; $p=0.02$ ), lack of multifocality $(O R$ 3.02; $p<0.001)$ and $p C R$ in the breast $(O R$ 1.97, $p=0.05$ ) remained statistically significant in the multivariate analysis. The results of the multivariate analysis are illustrated in - Table 2.

\section{Descriptive analysis of involved axillary lymph nodes before and after NACT}

The analysis of involved SLNs before NACT included patients from arm $A$ and arm B of the SENTINA trial. 926 of the 1022 patients in arms $A$ and $B$ were evaluable for this analysis. Patients were divided into four subgroups: hormone receptor positive and HER2/neu negative (luminal; 47.6\%), hormone receptor negative and HER2/ neu positive (HER2; 8.2\%), triple negative (TN, 27.9\%) and hormone receptor positive and HER2/neu positive (TP; $16.3 \%$ ).

$39.7 \%$ of the luminal, $28.9 \%$ of the HER2, $19 \%$ of the TN and $47 \%$ of the TP tumors had involved SLN before NACT ( $\triangleright$ Fig. 2). The analysis of involved axillary lymph nodes (SLN and non-SLN) after NACT included the 318 patients of arm B who were evaluable for this analysis as described above. $27.6 \%$ of the luminal, $8.7 \%$ of the HER2, $20 \%$ of the TN and $14.3 \%$ of the TP tumors had involved axillary lymph nodes after NACT ( $\mathbf{F i g}$. 3 ).

\section{Descriptive analysis of subgroups of special interest}

24 patients with a triple negative tumor achieved a PCR in the breast (34.3\%). Three of those 24 patients had involved lymph nodes after NACT $(12.5 \%)$. These 3 patients represent $1.2 \%$ of the 258 triple negative patients included in arms $A$ and $B$ of the SENTINA trial. 11 patients with a HER2/neu positive tumor achieved a PCR in the breast. One of those 11 patients had involved axillary lymph nodes after NACT (9.1\%). This patient represented $0.5 \%$ of the 227 HER2/neu positive population included in arms $A$ and $B$ of the SENTINA trial.

\section{Discussion}

In patients whose indication for chemotherapy is known already at the time of diagnosis neoadjuvant therapy has become a standard and is considered at least equally effective compared to adjuvant chemotherapy. Influential guidelines as the German AGO recommendations even classify neoadjuvant chemotherapy as superior to adjuvant chemotherapy whenever chemotherapy is indicated based on the information derived from the core biopsy. The neoadjuvant setting allows response-guided approaches as well as postneodjuvant therapies in cases of residual tumor [19]. This benefit is not limited to the primary tumor in the breast but is also applicable to involved axillary lymph nodes. The rate of axillary 


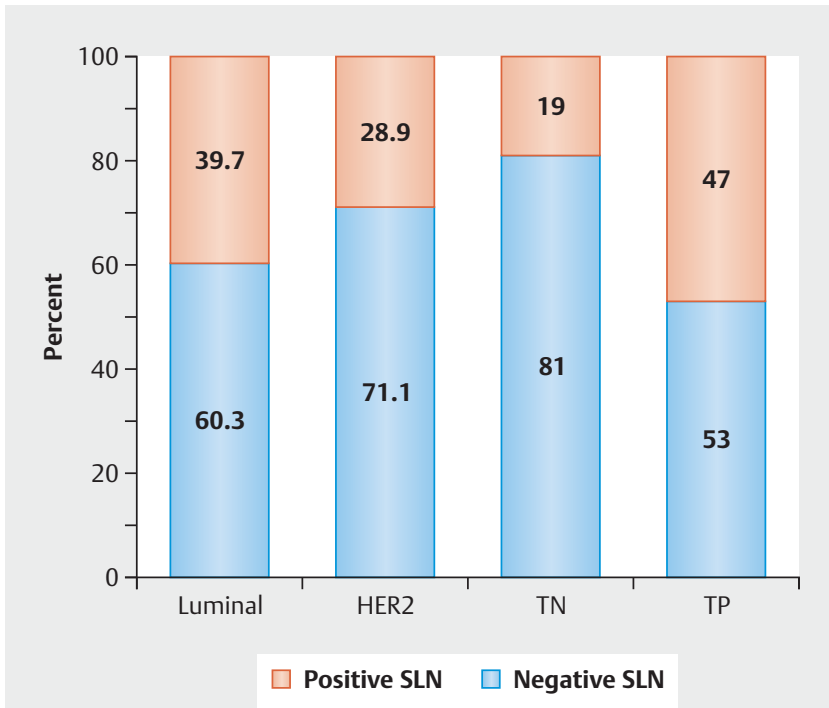

- Fig. 2 Percentage of positive SLN before NACT (all patients with clinically node negative disease at initial presentation (arms A and B).

downstaging after neoadjuvant chemotherapy has been reported to be up to $64.7 \%$ in selected subtypes such as HER2/neu positive cases [11]. It is generally accepted and has been repeatedly demonstrated that achieving a pCR after neoadjuvant chemotherapy is associated with an improved prognosis over all tumor biologies [14]. Trials discriminating between the impact of breast pCR on the one hand and node negative axillary status (ypNO) after NACT on the other hand have reported that the association between ypNO and prognosis is stronger than the influence of breast $\mathrm{PCR}$ [20].

It is important to acknowledge that during our analysis, only patients with clinically and sonographically negative axillary lymph nodes but involved SLN before NACT were included. This cohort has not been included in previous analyses regarding axillary downstaging and with unknown residual axillary burden after SLNB. Since the definitions of complete pCR (ypT0 ypNO) are not discriminating between patients with involved versus not involved lymph nodes at initial presentation [21], our results provide insight into a previously unreported group of patients and their probability of achieving ypNO-status. The reliability of our dataset was demonstrated by the expected associations between breast pCR and clinical/pathological parameters. On the other hand the reported association of $\mathrm{pCR}$ in the breast and ypNO was an expected result but does not help regarding prediction of a node negative status after NACT because this parameter only becomes accessible after the final pathological report of the breast specimen. For counseling patients prior to surgery after NACT only parameters known before surgery are useful.

$22.3 \%$ of patients with clinically occult nodal metastases in our analysis still have involved lymph nodes after NACT. Furthermore, a fraction of axillary disease is removed through SLNB and rates of clearance of a positive SLNB through NACT cannot be assessed by our approach. Therefore, rates of residual axillary burden after

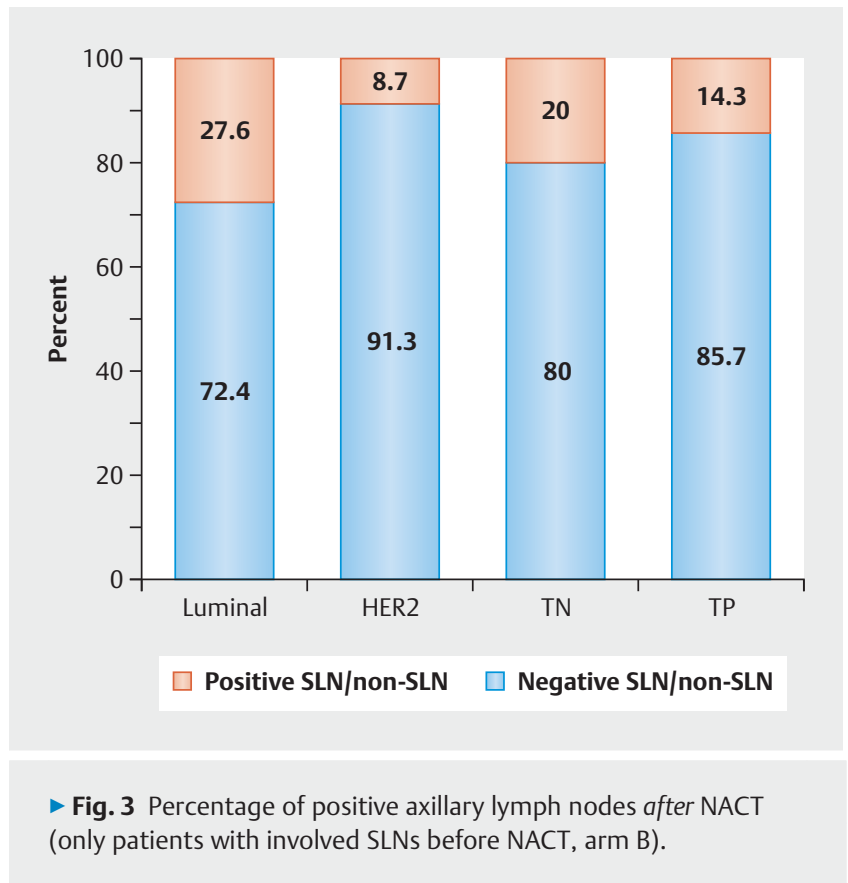

NACT may even be underestimated in our analysis. This underscores that general omission of any axillary surgery after neoadjuvant chemotherapy in all cases of clinically node negative disease at initial presentation is not an appropriate approach. Nevertheless we could demonstrate that patients with triple negative disease had the lowest risk for occult lymph node metastases at initial presentation in our analysis, followed by patients with HER2/ neu positive and hormone receptor negative tumors. Although we could analyze these data only in a descriptive manner (due to a low number of cases among those subgroups) our results do not justify more intense local intervention among patients with aggressive tumor biology. Although we found several statistically significant associations with a ypNO status, we cannot identify a subgroup for whom omission of axillary surgery after NACT can be safely recommended. However, it was remarkable that patients with a lobular morphology had a numerically lower rate of ypNO maybe indicating a previously postulated lower chemotherapy benefit in lobular breast cancer [22]. Our finding of a numerically increased percentage of ypNO in HER2/neu positive patients is in line with previous analyses, although in these analyses triple negative disease was also associated with an increased rate of axillary downstaging [11,23], an entity without significant association with ypNO in our study. However, our descriptive analyses are suggesting a remarkably low rate of residual axillary burden after NACT in triple negative (1.2\%) and HER2/neu positive patients $(0.5 \%)$ in case of a breast pCR. A recently published analysis of Arm C of the SENTINA study containing clinically node positive patients also demonstrated tumor biology to be the strongest predictor of nodal downstaging [16]. International guidelines recommend either axillary dissection, SLNB or targeted axillary dissection (TAD; the combination of SLNB and the removal of a lymph node with biopsy-proven involvement prior to NACT) after NACT as the optimal axillary management in patients with initially 
involved lymph nodes [19]. The ongoing AXSANA/EUBREAST-03 trial (ClinicalTrials.gov Identifier: NCT04373655) is evaluating different approaches in this setting in a multinational effort with regard to disease free survival and quality of life. This prospective trial will provide further data regarding the question if our findings can be transferred to the clinically node positive situation.

Limitations of our study include the retrospective character of the analysis, the exploratory statistical analysis and the rather small patient cohort. Furthermore, we underscore that by SLN prior to NACT, a fraction of nodal disease is removed and conversion of the SLN metastasis by NACT cannot be assessed. Therefore, our analysis allows us to assess the association between clinical/pathological parameters and rates of residual axillary burden rather than true SLN conversion.

Finally, the rate of triple negative patients in our study population was with $15 \%$ rather small for a cohort treated with neoadjuvant chemotherapy whereas the HER2/neu positive rate was $27 \%$, an expected rate in the neoadjuvant setting. This limitation may be one of the factors explaining the lacking association between triple negative disease and ypN0. Our descriptive analysis of arms $A$ and $B$ of the SENTINA trial included $27.9 \%$ triple negative and $24.5 \%$ HER2/neu positive patients and revealed a remarkably low rate of residual axillary burden in case of a breast PCR but has to be interpreted very cautiously because of the descriptive character of the analysis.

After the evolution of current guidelines, recommending SLNB after NACT in patients with clinically node negative axillary lymph nodes at first presentation [19], the setting as described in our analysis, i.e. with SLNB before NACT, should have become an exception. However, we still believe our data may have an impact on the development of further prospective clinical trials, as they allow an estimate regarding the risk of axillary involvement after NACT in cases of initially node negative disease. Studies as e.g. the EUBREAST-01 study (ClinicalTrials.gov Identifier: NCT04101851) will answer the question if in selected tumor subtypes such as HER2/ neu positive and triple negative tumors axillary surgery can be safely omitted after neoadjuvant chemotherapy in cases of clinically node negative breast cancer.

\section{Conclusions}

Our analysis demonstrates that patients enrolled in the SENTINA trial with clinically negative axilla and a positive SLN prior to NACT show positive axillary nodes in $22.3 \%$ of cases after NACT. We acknowledge that we cannot draw a conclusion regarding the influence of NACT on SLN conversion, since the SLN was excised as part of axillary staging prior to NACT. Although we found statistically significant associations between PCR in the breast and numerous clinical/pathological parameters, only the association between extranodal spread, lack of multifocality and pCR in the breast and residual axillary involvement after NACT were statistically significant. We cannot clearly identify a subset of patients for whom axillary surgery after NACT could be safely omitted if SLNs were positive before systemic therapy. In a descriptive analysis we found only $1.2 \%$ of triple negative and $0.5 \%$ of HER2/neu positive patients to have residual axillary burden in case of a breast $P C R$. Our data are well in line with recently presented data demonstrat- ing that the association between PCR in the breast and free axillary nodes after NACT is particularly strong in patients with TN and HER2 positive tumors. This question will be addressed in future trials currently under development.

\section{Role of the Funding Source}

The SENTINA trial received financial and logistic support from AGO-B, Brustkrebs Deutschland and the German Breast Group (GBG).

\section{Conflict of Interest}

The authors declare that they have no conflict of interest.

\section{References}

[1] Fisher B, Bauer M, Wickerham DL et al. Relation of number of positive axillary nodes to the prognosis of patients with primary breast cancer. An NSABP update. Cancer 1983; 52: 1551-1557

[2] Curigliano G, Burstein HJ, Winer EP et al. De-escalating and escalating treatments for early-stage breast cancer: the St. Gallen International Expert Consensus Conference on the Primary Therapy of Early Breast Cancer 2017. Ann Oncol 2018; 29: 2153. doi:10.1093/annonc/mdx806

[3] Reimer T, Engel J, Schmidt M et al. Is Axillary Sentinel Lymph Node Biopsy Required in Patients Who Undergo Primary Breast Surgery? Breast Care (Basel) 2018; 13: 324-330. doi:10.1159/000491703

[4] Engel J, Emeny RT, Hölzel D. Positive lymph nodes do not metastasize. Cancer Metastasis Rev 2012; 31: 235-246

[5] Sparano JA, Gray R], Makower DF et al. Adjuvant Chemotherapy Guided by a 21-Gene Expression Assay in Breast Cancer. N Engl J Med 2018; 379: 111-121. doi:10.1056/NEJMoa 1804710

[6] Cardoso F, van't Veer LJ, Bogaerts J et al.; MINDACT Investigators. 70Gene Signature as an Aid to Treatment Decisions in Early-Stage Breast Cancer. N Engl J Med 2016; 375: 717-729. doi:10.1056/NEJMoa 1602253

[7] Albain KS, Barlow WE, Shak S et al.; Breast Cancer Intergroup of North America. Prognostic and predictive value of the 21-gene recurrence score assay in postmenopausal women with node-positive, oestrogenreceptor-positive breast cancer on chemotherapy: a retrospective analysis of a randomised trial. Lancet Oncol 2010; 11: 55-65. doi:10.1016/ S1470-2045(09)70314-6

[8] Giuliano AE, Hunt KK, Ballman KV et al. Axillary dissection vs. no axillary dissection in women with invasive breast cancer and sentinel node metastasis: a randomized clinical trial. JAMA 2011; 305: 569-575

[9] Reimer T, Stachs A, Nekljudova V et al. Restricted Axillary Staging in Clinically and Sonographically Node-Negative Early Invasive Breast Cancer (c/iT1-2) in the Context of Breast Conserving Therapy: First Results Following Commencement of the Intergroup-Sentinel-Mamma (INSEMA) Trial. Geburtshilfe Frauenheilkd 2017; 77: 149-157. doi:10.1055/ s-0042-122853

[10] Kuehn T, Bauerfeind I, Fehm T et al. Sentinel-lymph-node biopsy in patients with breast cancer before and after neoadjuvant chemotherapy (SENTINA): a prospective, multicentre cohort study. Lancet Oncol 2013; 14: 609-618

[11] Boughey JC, Suman V], Mittendorf EA et al.; Alliance for Clinical Trials in Oncology. Sentinel lymph node surgery after neoadjuvant chemotherapy in patients with node-positive breast cancer: the ACOSOG Z1071 (Alliance) clinical trial. JAMA 2013; 310: 1455-1461. doi:10.1001/jama.2013.278932 
[12] Classe JM, Loaec C, Gimbergues P et al. Sentinel lymph node biopsy without axillary lymphadenectomy after neoadjuvant chemotherapy is accurate and safe for selected patients: the GANEA 2 study. Breast Cancer Res Treat 2019; 173: 343-352. doi:10.1007/s10549-018-5004-7

[13] Rao R, Euhus D, Mayo HG et al. Axillary node interventions in breast cancer: a systematic review. JAMA 2013; 310: 1385-1394

[14] Cortazar P, Zhang L, Untch M et al. Pathological complete response and long-term clinical benefit in breast cancer: the CTNeoBC pooled analysis. Lancet 2014; 384: 164-172. doi:10.1016/S0140-6736(13)62422-8

[15] Shi ZQ, Qiu PF, Liu YB et al. Neo-adjuvant chemotherapy and axillary deescalation management for patients with clinically node-negative breast cancer. Breast J 2019; 25: 1154-1159. doi:10.1111/tbj.13422

[16] Liedtke C, Kolberg HC, Kerschke L et al. Systematic analysis of parameters predicting pathological axillary status (ypN0 vs. ypN+) in patients with breast cancer converting from $\mathrm{cN}+$ to ycN0 through primary systemic therapy (PST). Clin Exp Metastasis 2018; 35: 777-783

[17] Samiei S, van Nijnatten TJA, de Munck L et al. Correlation Between Pathologic Complete Response in the Breast and Absence of Axillary Lymph Node Metastases After Neoadjuvant Systemic Therapy. Ann Surg 2020; 271: 574-580. doi:10.1097/SLA.0000000000003126
[18] R Core Team. R: A language and environment for statistical computing. Vienna, Austria: R Foundation for Statistical Computing; 2019. Accessed February 02, 2019 at: https://www.R-project.org/

[19] Ditsch N, Untch M, Thill M et al. AGO Recommendations for the Diagnosis and Treatment of Patients with Early Breast Cancer: Update 2019. Breast Care (Basel) 2019; 14: 224-245. doi:10.1159/000501000

[20] Classe JM, Bordes V, Campion L et al. Sentinel lymph node biopsy after neoadjuvant chemotherapy for advanced breast cancer: results of Ganglion Sentinelle et Chimiotherapie Neoadjuvante, a French prospective multicentric study. J Clin Oncol 2009; 27: 726-732. doi:10.1200/ JCO.2008.18.3228

[21] von Minckwitz G, Untch M, Blohmer JU et al. Definition and impact of pathologic complete response on prognosis after neoadjuvant chemotherapy in various intrinsic breast cancer subtypes. J Clin Oncol 2012; 30: 1796-1804. doi:10.1200/JCO.2011.38.8595

[22] Marmor S, Hui JYC, Huang JL et al. Relative effectiveness of adjuvant chemotherapy for invasive lobular compared with invasive ductal carcinoma of the breast. Cancer 2017; 123: 3015-3021. doi:10.1002/cncr.30699

[23] Kantor O, Sipsy LM, Yao K et al. A Predictive Model for Axillary Node Pathologic Complete Response after Neoadjuvant Chemotherapy for Breast Cancer. Ann Surg Oncol 2018; 25: 1304-1311. doi:10.1245/s10434018-6345-5

\section{Correction}

Residual Axillary Burden After Neoadjuvant Chemotherapy (NACT) in Early Breast Cancer in Patients with a priori Clinically Occult Nodal Metastases - a transSENTINA Analysis

Hans-Christian Kolberg, Thorsten Kühn, Maja Krajewska, Ingo Bauerfeind, Tanja N. Fehm, Barbara Fleige, Gisela Helms, Annette Lebeau, Annette Stäbler, Sabine Schmatloch, Maik Hauschild, Lukas Schwentner, Peter Schrenk, Sibylle Loibl, Michael Untch, Cornelia Kolberg-Liedtke Geburtsh Frauenheilk 2020; 80: 1229-1236 doi:10.1055/a-1298-3453

In the above mentioned article a co-author's name was misspelled. The correct name is: Maik Hauschild. 